
do algned for use in the space environment. They often require a

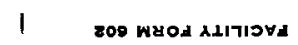
number of well-regulated supply voltages to insure satisfactory operation. Since the se voltages are generally not available from the main space craft power supply, a DC to DC converter and regulator is usually employed. Typical currently available converter-regulator designs have an efficiency of 70 to 75 percent at the 1 watt level and 80 to 90 percent at the 10 watt level. The se designs usually deveiop maximum efficiency for only a limited range of output power ciose to the maximum levei. Thus, particularly in applications where wide variations in required power level are anticipated, many of the adrantages of iow power circuitry are negated by converterregulator inefficiencies. This paper presents a design technique for converter-regulators which overcomes some of the limitations inherent in many previous types.

The essential elements of typical currently available high efficiency $D C$ to $D C$ converter-regulators are shown in the block diagram of Figure 1. Multipie output voltages are obtained by rectifying the outputs from a conventional DC to AC converter, consisting of a solid state chopper and a transformer with multiple outputs. Feedback from one or more of the 
output voltages is applied to a pre-regulator which controls the input voltage to the $D C$ to $A C$ converter in order to maintaln the derired output voltages.

A majority of the losses in a converter of this type, particularly when operating at a fraction of maximum output power, arise in the DC to AC converter section, since the operating frequency of this element is essentially independent of the power level. Thus, as output power is reduced, core los seo dissipate an increasingly larger fraction of the total input power.

In any application where the input voltage is not extremely well regulated, pre-regulation is accompllshed with a sitch driving a resonant charging network since the inofficiencies inherent in a disalpative regulator operating over a wide dynamic range are intolerable. Two methods for effecting resonant regulation are shown in Figure 2. The first method

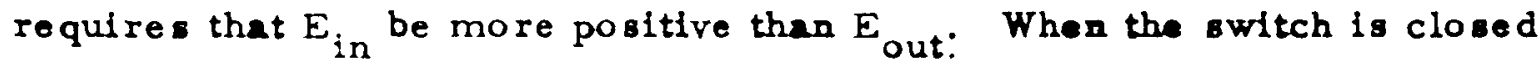
current increases in the inductor, charging the output capacitor and storing magnetic energy in the inductor. When the switch opens the diode shorts due to inductor voltage flyback, permitting transfer of the energy stored in the inductor to the capacitor. In the second configuration, current also increases in the inductor when the witch is closed. The energy stored in the inductor is transferred to the output capacitor through the dode when the switch is opened. Both of these methods provide theoretically losalese converaton from one voltage level to another, since the cycle ende when Inductor current, and thus the energy tored in the lnductor, is zero. In oither case, control of $E_{\text {out }}$ is achleved by varying owitch duty cycle.

Examination of the second method of accomplishing resonant regulation

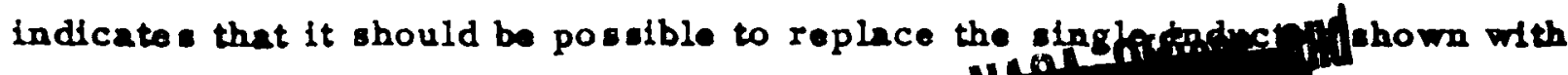

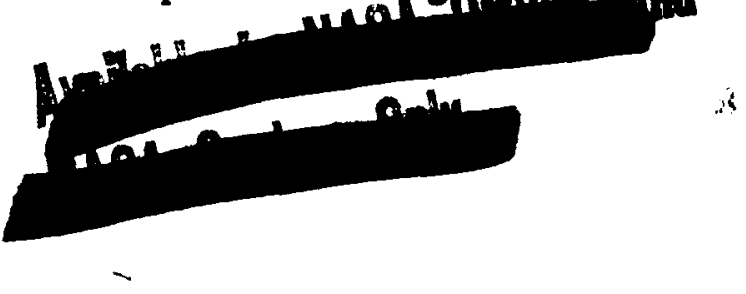


a tapped inductor and include additional diodes and capicitora. If the various output taps are tightly coupled, multiple output voltages can be obtained which are related by the turns ratios of the various taps. It is also possible to store magnetic onergy in the primary magnetizing inductance of a transformer with multiple secondary winding $\$$, as shown in Figure 3. Assuming zero leakage inductances for the tranaformer, the various output voltages are simply related by the relattve turns ratios among the multiple secondary windings. Slnce onergy in placed on the output capacitor during flyback, the output roltage can be controlled independently from the input voltage. Thus the banic method permits both regulation and conversion to multiple output voltages in a single stage. If the switch drive is arranged so that a constant onergy is transferred from the input to the output on each cycle of operation, the output roltage can be regulated by varying the frequency of operation of the switch. In this case, conversion losses are directly related to the power being transferred, permitting a design with efficiency which is essentially independent of operating power level.

The first prototype of a power supply utilixing this principle employed a blocking oscillator as the energy transfer element. ${ }^{2}$ This design had the advantage of extreme simplicity (only two transistors were used) but the maximum officiency obtained was only 70 percent at the $200 \mathrm{mw}$ level. The inefficiency resulted primarlly from rather poor control of the witch transistor in the blocking oscillator configuration.

A detailed block diagram for 2 more recently tested version is shown in Fygure 4. One of the seven output voltages is compared with a xener reforence, and the error signal applied to a voltage to frequency converter. This $v$ to $f$ converter has extremely sharp characteriatica; with the 12 volt output approximately $50 \mathrm{mv}$ below the reference, the frequency output is a maximum ( $30 \mathrm{KC}$ for the experimental model) while a $50 \mathrm{mr}$ high voltage 
cuts off the $v$ to $f$ converter. Since the roference network and the atatic power requirements of the $v$ to $f$ converter must be supplied continuously and thus represent a power overhead, these circuits are designed for extremoly low power operation, with a combined dissipation of approximately $250 \mu \mathrm{w}$. Output pules from the $v$ to $f$ converter trigger a one-shot multivibrator which drives the switch transistor. Since the static power requirements of the one-shot must be supplied continuously, a monostable veraion of the basic four transistor complementary switching circuit ${ }^{3}$ is used which results in a static diselpation of approxdmately $50 \mathrm{\mu w}$. Output pulse width of the one-shot is inversely related to the input supply roltage in order to keep the energy tranaforred from input to output per cycle constant. Thus the frequency of operation is linearly related to the power being delivered to the load.

The experimental converter described abovo delivers a maximum power of one watt. Total dissipation with no load connected to the converter is approximately $0.5 \mathrm{mw}$. When the converter is loaded with equal value resistors connected between the $+12,+6$, and -9 volt outputs and ground, an incremental efficiency in excess of 84 percent is obtained. The efficiency for any operating power level can be obtained from the empirical relationahip

$$
\eta=\frac{\text { Power Out }}{\text { Power In }}=\frac{\text { Power Out }}{(1.19) \text { Power Out }+5 \times 10^{-4}}
$$

where all powers are expressed in watts. Thus, for example, an efficlency exceeding 80 percent is obtained at a $10 \mathrm{mw}$ output power level.

The converter function. adequately with no measurable change in efficiency for input voltage variations from 10 to 30 volts. The +12 
volt uatput is the best regulated since feedback is obtained from this ultput. Reguiation of the +12 volt output is within \pm 2 percent for all combinations of output power and input voltage teated over the temperature range of $-60^{\circ} \mathrm{C}$ to $+110^{\circ} \mathrm{C}$. Regulation of the other outputs is somewhat poorer due primarily to transformer leakage inductance. However, if the ratios of currents supplied from the various output voltages are maintained constant within a factor of $2: 1$, regulation to within \pm 10 percent is obtained from the 3 volt outputs, with regulation for all other outputs to within \pm 5 percent.

Approximately half of the converter incremental lossos are attributable to the forward drops of the output diodes. Thu it seems that a further increase in efficiency can be obtained by using synchronous rectification. Additionally, carefui redesign of the reference network, $v$ to $f$ converter and one-shot should reduce the power overhead to $0.2 \mathrm{mw}$ or less.

\section{Acknowledg ment}

This wurk was supported under NASA Research Grant, NSG-234-61. The authur is grateful to J.A. Bosco for his helpful comments concerning the basic design. 


\section{BIB LIOGRAPHY}

1 Schmidt, W. G., et al, "Electronic Instrumentation of Gamma-Ray Telescope Aboard Orbiting Solar Observatory S-57," Record of the 1964 International Space Electronics Symposium, October, 1964.

2 Warakomsky, R.E., "A Regulated Power Supply for Spacecraft Use," Massachusetts Institute of Technology S. B. Thesis, June, 1964.

3 Baker, R.H., "Maximum Efficiency Transistor Switching Circuits," Lincoln Laboratory Report No. 110, March, 1956. 


\section{CAPTIONS}

Figure 1 - Conventional DC to DC converter and regulator.

Figure 2 - Two methods for resonant regulation.

Figure 3 - Method for achieving regulation and conversion to multiple voltages in a single stage.

Figure 4 - Block diagram of experimental 1 watt converter-regulator. 


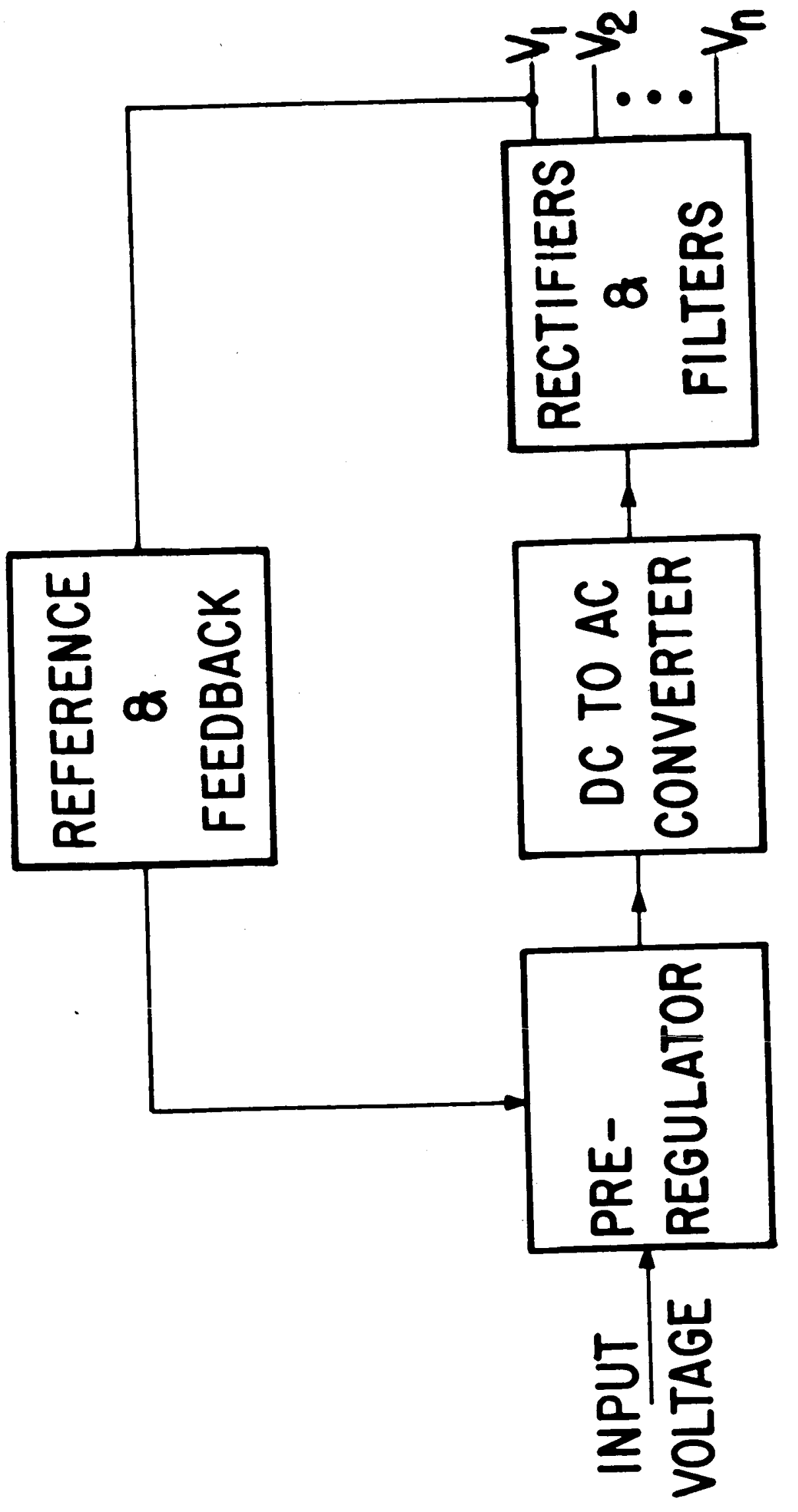

$\frac{5}{4}$ 


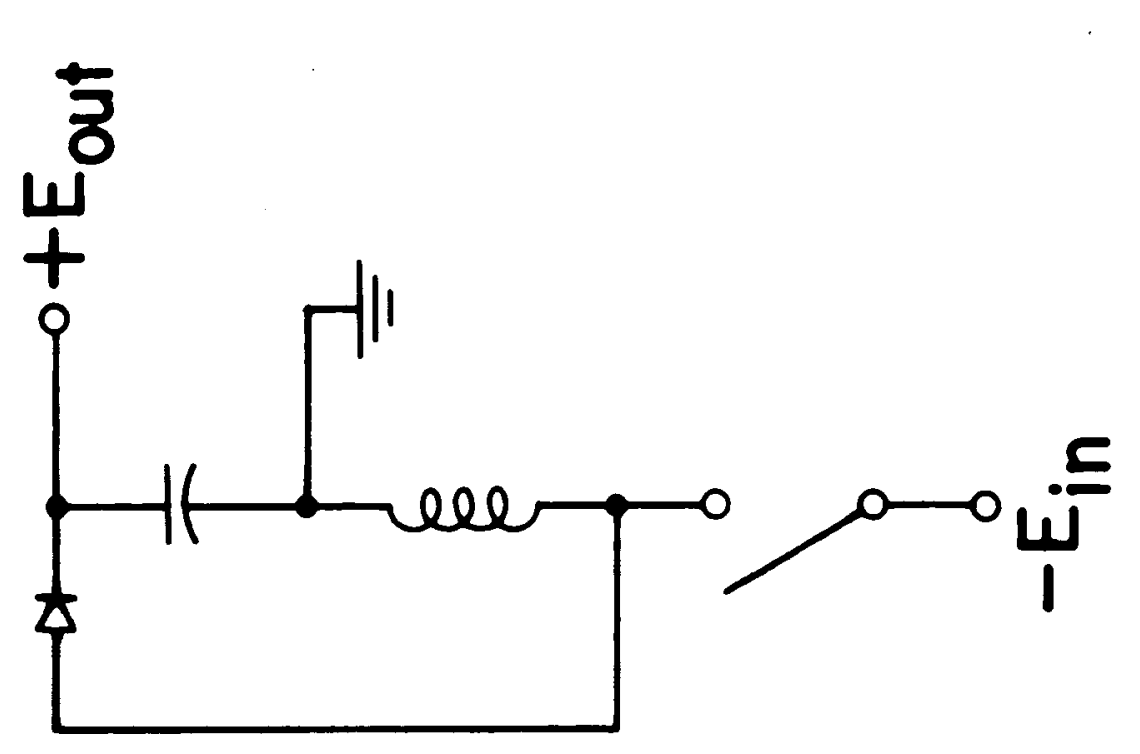

$\frac{N}{4}$

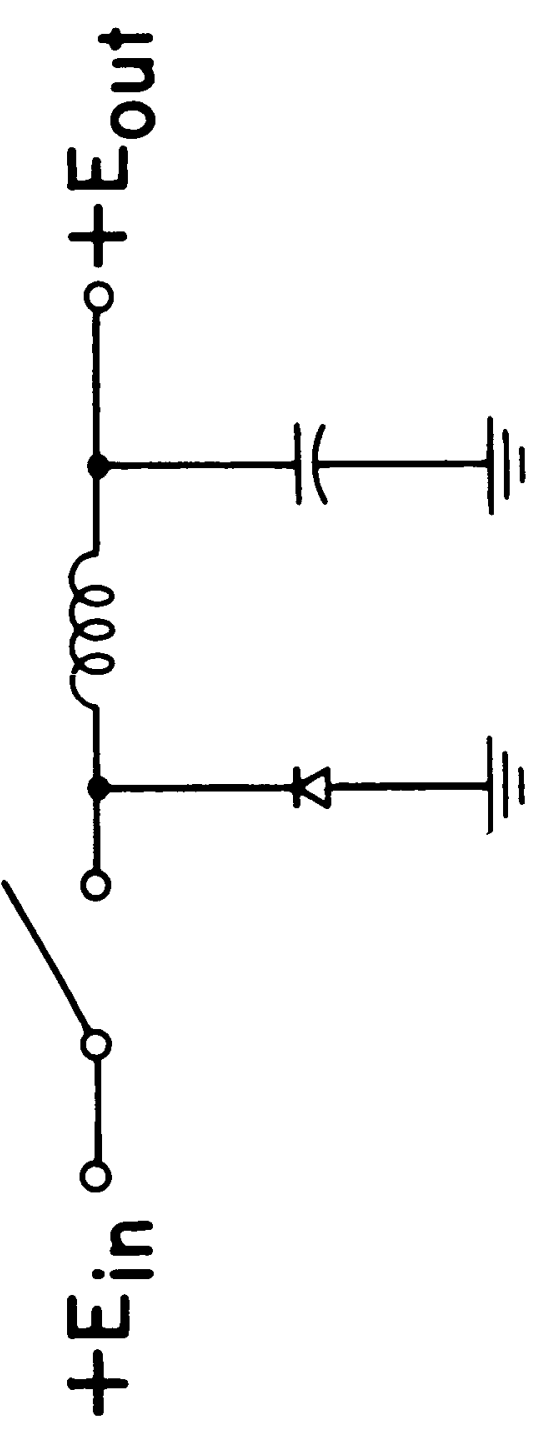




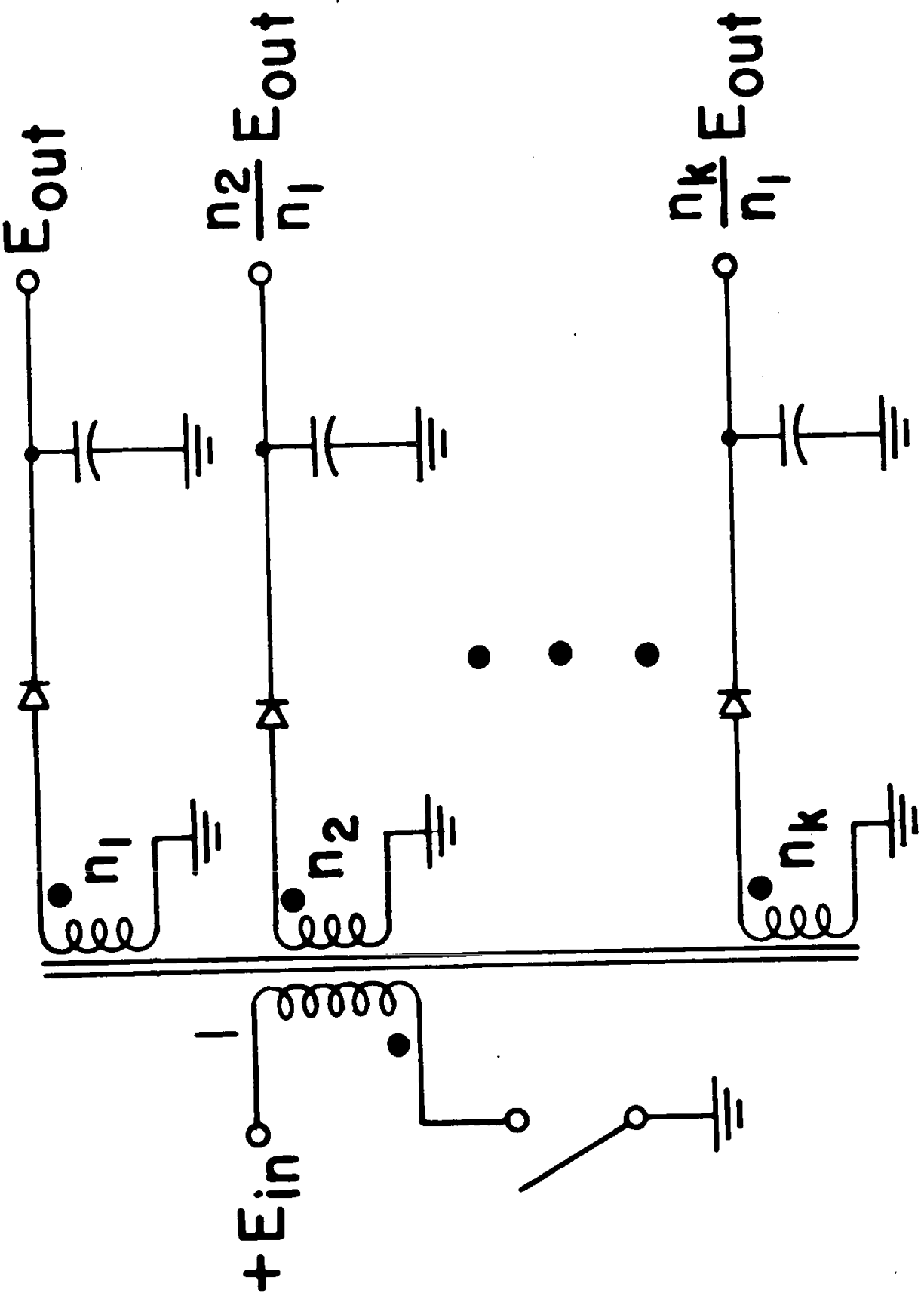




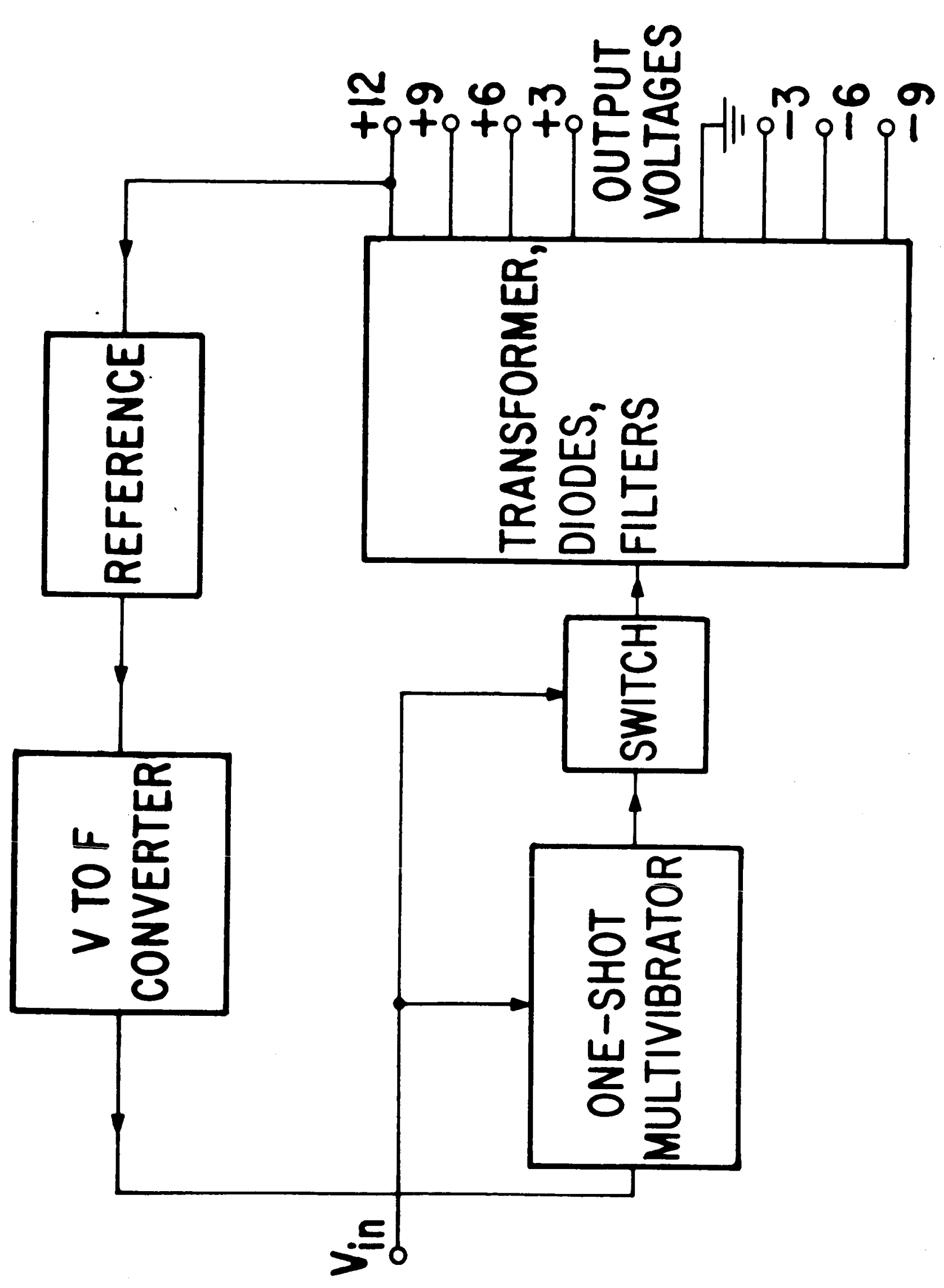

8
$\frac{0}{4}$ 